\title{
Microstructural Characterization in the Ni-Ti-Cu System Produced by Mechanical Alloying
}

\author{
M. T. Ochoa-Lara, H. Flores-Zúñiga, I. Estrada-Guel and R. Martínez-Sánchez. \\ Centro de Investigación en Materiales Avanzados (CIMAV), Miguel de Cervantes No.120, C.P. \\ 31109, Chihuahua, Chih., México.
}

Ti-Ni alloys exhibit good properties in strength, ductility, resistance to corrosion and biocompatibility, which are important for practical use, in addition to excellent shape memory effect characteristics. Ti-Ni alloys present the shape memory effect (SME) in near equiatomic composition. Particularly, substitution of copper for nickel to obtain the ternary TiNiCu alloy, improves shape memory and pseudoelasticity characteristics. Ti-Ni-Cu alloys with $\mathrm{Cu}$ contents from 1 to $5 \%$ exhibit a reduction in the transformation hysteresis, which is very important for obtaining memory properties. On the other hand, the martensitic transformation temperature (Ms) does not change significantly. The $\boldsymbol{R}$ (rhombohedral) - phase transformation in Ti-Ni alloys produces a reduction of the shape memory strain, and small additions of copper can prevent this $\boldsymbol{R}$ phase transition.

There are many routes to synthesize new alloys; Mechanical Alloying (MA) is one of them. There are too many reports in the literature about this system, however there are very few reports using the MA process. The MA process has proved to be an effective method to develop materials with novel structures. These can be solid solutions (even in immiscible systems), amorphous phases, fine particle sized and nanometric crystals, etc.; these novel structures are responsible for the special physical and chemical properties observed in mechanically alloyed products.

$\mathrm{Ni}$, Ti and $\mathrm{Cu}$ (99.9\% purity, -200 mesh in size) crystalline powders were used as raw materials, to synthesize the mechanical alloyed powders. Each mixture was mechanically alloyed in a highenergy shaker type mill (SPEX-8000M) during different milling times. Experimental milling operations were dry-conducted under inert argon atmosphere and room temperature.

Milling time has a direct effect on the microstructure of milled materials, as show in Figure 1. As the milling time is increasing the peaks are shifting, broadening and shortening, indicating the formation of real alloy as a consequence of high-energy impacts occurred between balls and sample particles during MA. Copper is dissolved into Ti and Ni matrix as the milling time is increased.

As was expected, the surface morphology was changed during the milling process, as well as the size of the particles of the sample. The morphology evolution is shown in Figure 2, notice the smaller size in particles for longer milling times. Additionally, as the milling time increases, the homogeneity in particles of the samples is increasing as well; as developed the EDS microanalyses performed in milled powders.

The variation values in the chemical composition of the processed powders is presented in Table I, notice the small content variation as a function of the milling time. After longer milling times $\mathrm{Fe}$ contamination was found lower than $0.2 \mathrm{wt}$ \% as reported by EDS microanalyses. 


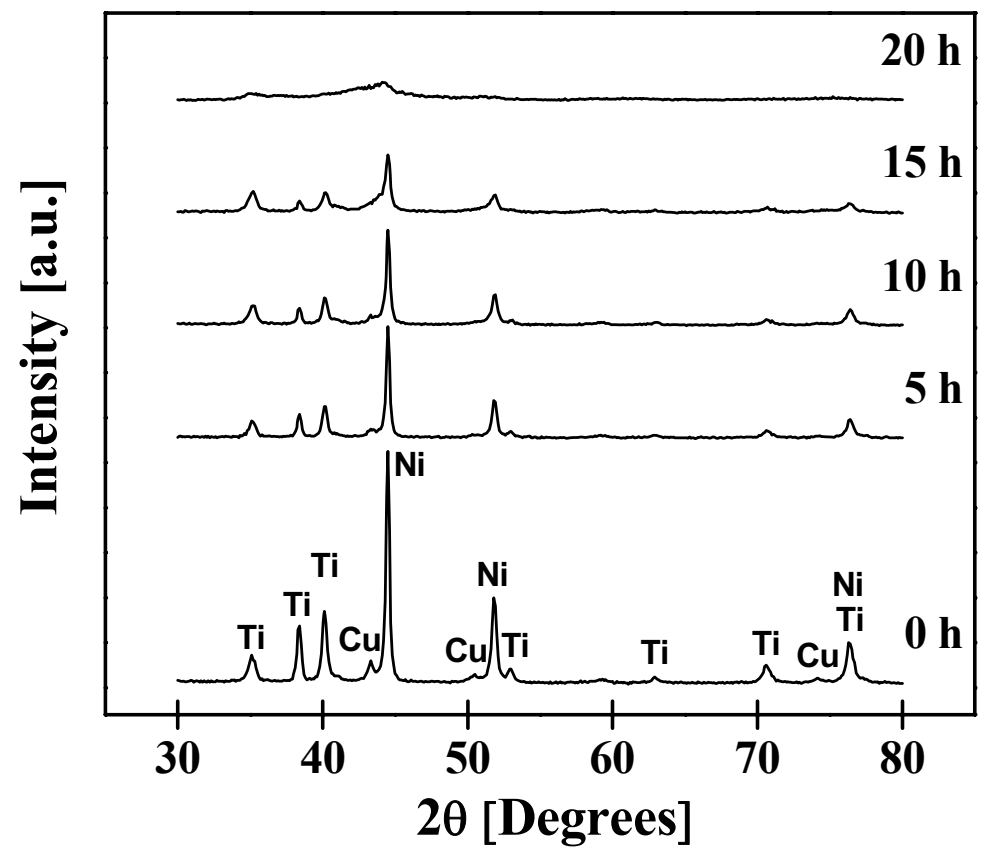

Figure 1.- XRD patterns from mixed and processed powders at different milling times.

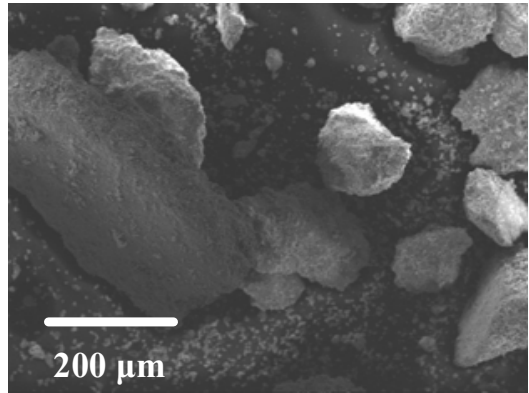

$5 \mathrm{~h}$

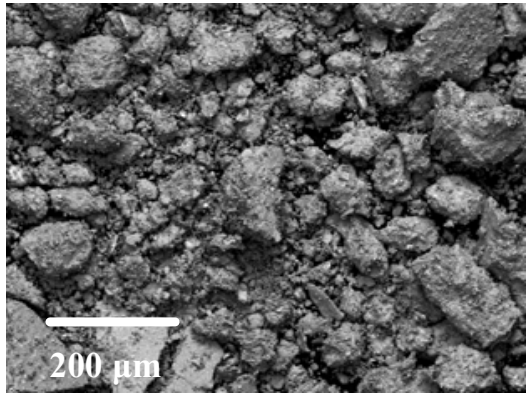

$10 \mathrm{~h}$

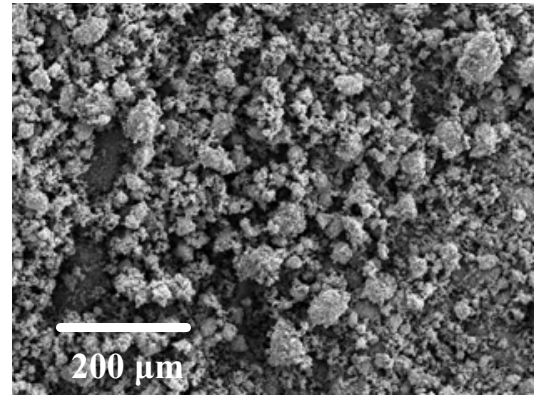

$20 \mathrm{~h}$

Figure 2.- Representative SEM micrographs, showing morphology evolution in as-milled powders.

Table I.- Variation in Ti-Ni-Cu contents (in at. percent) as a function of milling time.

\begin{tabular}{|c|c|c|c|}
\hline $\begin{array}{c}\text { Milling } \\
\text { Time }[\mathbf{h}]\end{array}$ & Titanium & Nickel & Copper \\
\hline $\mathbf{0}$ & 54,52 & 34.97 & 10.51 \\
\hline $\mathbf{5}$ & 50.19 & 38.97 & 10.85 \\
\hline $\mathbf{1 0}$ & 51.61 & 37.33 & 11.06 \\
\hline $\mathbf{1 5}$ & 50.90 & 37.63 & 11.47 \\
\hline $\mathbf{2 0}$ & 47.06 & 45.93 & 7.01 \\
\hline
\end{tabular}

